\title{
Improving the methodology for assessing labour potential in socio-economic systems based on the organizational and methodological model
}

\author{
Maryna Savchenko ${ }^{1 *}$, Larysa Shaulska ${ }^{2}$, Olga Shkurenko ${ }^{3^{*}}$ and Larysa Sarkisyan ${ }^{1}$ \\ ${ }^{1}$ Vasyl Stus Donetsk National University, International Economic Relations Department, Akademik \\ Yangel st. 4, 21007, Vinnytsa, Ukraine \\ ${ }^{2}$ Vasyl Stus Donetsk National University, Management and Behavioural Economics Department \\ Akademik Yangel st. 4, 21007, Vinnytsa, Ukraine \\ ${ }^{3}$ State University of infrastructure and technology, Business Logistics and Transport Technologies \\ Department, Ogienko st. 19, 03049, Kyiv, Ukraine
}

\begin{abstract}
The article examines the methodological approaches to the assessment of the labour potential of the socio-economic system. On the basis of the research, it has been established that the proposed algorithm for assessing the labour potential of the socio-economic system at the micro level. The approbation of the methodology for assessing the labour potential of the socio-economic system was carried out on the basis of the performance of an industrial enterprise. To improve the methodology for assessing the labour potential of socio-economic systems, the use of an organizational and methodological model for assessing the labour potential of the system has been proposed. The use of the organizational and methodological model is carried out in several stages: the construction of the Ishikawa diagram, the rating score, the construction of the Pareto diagram and the conduct of the $\mathrm{ABC}$ analysis. The implementation of the organizational and methodological model for assessing the labour potential of the socio-economic will allow for the effective management of the labour potential of the system and, as a result, will increase its competitiveness in the information economy.
\end{abstract}

\section{Introduction}

The effective functioning of any socio-economic system depends on the human resources at its disposal. Describing human resources as a human potential for labour, most scientists associate this category with the concept of "labour potential" - the possible quantity and quality of labour that society (labour collective) has at a given level of science and technology development [1, p. 324].

The economic category "labour potential" was formed in the 1970s to express a generalizing assessment of personnel, taking into account not only its actual characteristics but also reserves and potential.

*Corresponding author: $\underline{\mathrm{m} \_s a v c h e n k o @ \text { donnu.edu.ua, dondyy@ukr.net }}$ 
The most developed under the labor potential of the socio-economic system is based on the professional knowledge, practical skills, personal and psychophysiological characteristics of workers, the ability to make the required contribution to the realization of the enterprise's goals, with proper material, technical, informational and organizational support of the labor process [2, p. 20].

Since its inception, this category has undergone an evolutionary path of development from its complete identification with labour resources to its presentation as a set of abilities to work. However, the question of the development of a practically reasonable methodology for the effective assessment of the labour potential of a socio-economic system at any level remains important.

\section{Degree of Problem Development}

The development of methods for analyzing the labour potential of the enterprise was carried out by many leading scientists. In particular, scientists A. Ledneva [3] dealt with the analysis and evaluation of the labor potential of industrial enterprises, E. Lipatova, Y. Yukhtanova [4], V. Potudanskaya, L. Trunking [5], A. Fleenko [6], N. Hadasevich [7].

Despite the development of methods for analyzing the labour potential of the socioeconomic system, many issues remain unresolved. This fact encourages us to conduct further theoretical, methodological and practical research in this scientific direction.

The purpose of the study is to develop the methodology, theoretical, methodological and practical recommendations and approaches to the assessment of the labour potential of the socio-economic system.

\section{Research results}

The labour potential of the socio-economic system should be considered as the synergistic ability of its labour resources to the effective functioning of activities and the achievement of certain productivity of them, which depends on the complex of social, communication, organizational, economic, logistical and other capabilities of the enterprise [8].

A generalized assessment of the labour potential of the socio-economic system should be carried out using the integral indicator $\left(\boldsymbol{I}_{\boldsymbol{L} P}\right)$, which is determined by the formula:

$$
I_{L P}=f\left(T_{p} ; T_{s} ; T_{o} ; T_{m} ; T_{c}\right)
$$

where $\boldsymbol{T}_{\boldsymbol{p}}$ - the complex indicator of the personnel component of the labour potential;

$\boldsymbol{T}_{\boldsymbol{s}}$-complex indicator of the component of social security and security of labour potential;

$\boldsymbol{T}_{\boldsymbol{o}}$ - the complex indicator of the organizational component of the labour potential;

$\boldsymbol{T}_{\boldsymbol{m}}$ - complex indicator of the motivational component of the labour potential;

$\boldsymbol{T}_{\boldsymbol{c}}$-complex indicator of the creative and intellectual component of the labour potential.

To improve the methodology for assessing the labour potential of socio-economic systems on the basis of the proposed use of the organizational and methodological model for assessing the labour potential of the socio-economic system (Fig. 1).

For practical testing, methodological tools have been proposed and the rationale for each stage of the assessment of the labour potential of the socio-economic system has been carried out.

Stage 1. Construction Ishikawa diagrams.

Ishikawa diagram is a graphical way of researching and determining the most significant causal relationships between factors and consequences in a situation or problem under investigation. This diagram allows you to identify key relationships between various factors and more accurately understand the process being studied. The diagram contributes to the 
determination of the main factors causing the most significant contribution to the one under consideration and to the prevention or elimination of their actions.

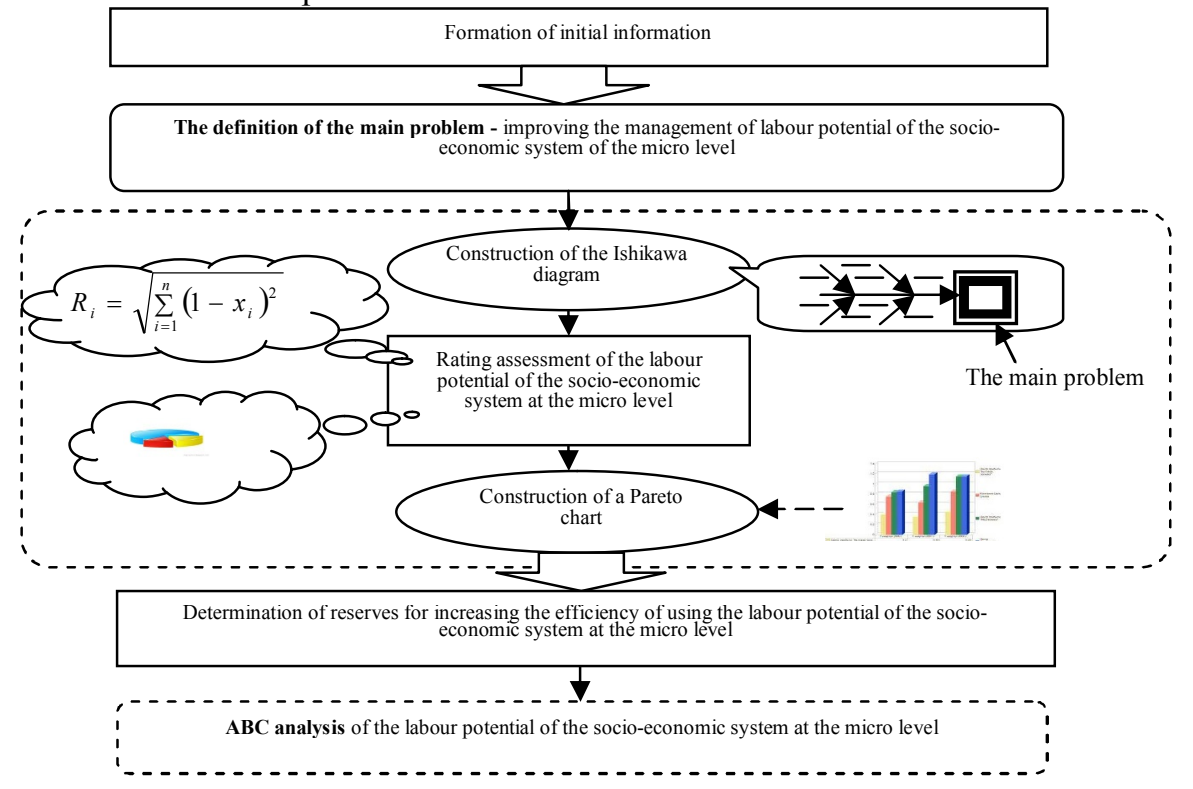

Fig. 1. The organizational model for assessing the labour potential of the socio-economic system

The Ishikawa diagram is used as an analytical tool to view the effects of possible factors and to highlight the most important causes, the effects of which give rise to specific consequences and are manageable.

Note that the Ishikawa diagram is a unique tool that allows you to create a system of indicators to assess the labour potential of the enterprise. Work with the Ishikawa diagram is carried out in several stages:

1. Identification and collection of all factors and causes, in any way, affect the studied result.

2. Grouping of factors by semantic and causal blocks.

3. Ranking of these factors within each block.

4. Analysis of the resulting picture.

5. "Liberation" of factors that cannot be affected.

6. Ignoring insignificant and unprincipled factors.

The study of the policy of management and positioning of the socio-economic system shows that the effectiveness of the system's activity is determined by the level of its employment potential. This, in turn, made it possible to single out the main problem of the system, which is to increase the level of the labour potential of the socio-economic system. The use of the Ishikawa diagram (Fig. 2) allows us to identify the main problem and detailing factors that influence this problem.

Stage 2. Rating evaluation of the labour potential of the socio-economic system.

At this stage, an effective tool for assessing the management of labour potential of the socio-economic system is the "radar of labour potential". "Labour potential radar" is a method of assessing the state of labour potential management, aimed at identifying weak points in the entire system of relations inherent in the management of labour potential.

The "labour potential radar", namely, the graphics-analytical method of analysis, makes it possible to systematically establish quantitative and qualitative links between individual elements of labour potential, its level of development and competitiveness, and on the basis of this, timely justify and implement management decisions to improve the functioning of 
the socio-economic system. It has several specific theoretical aspects that must be considered when justifying management decisions.

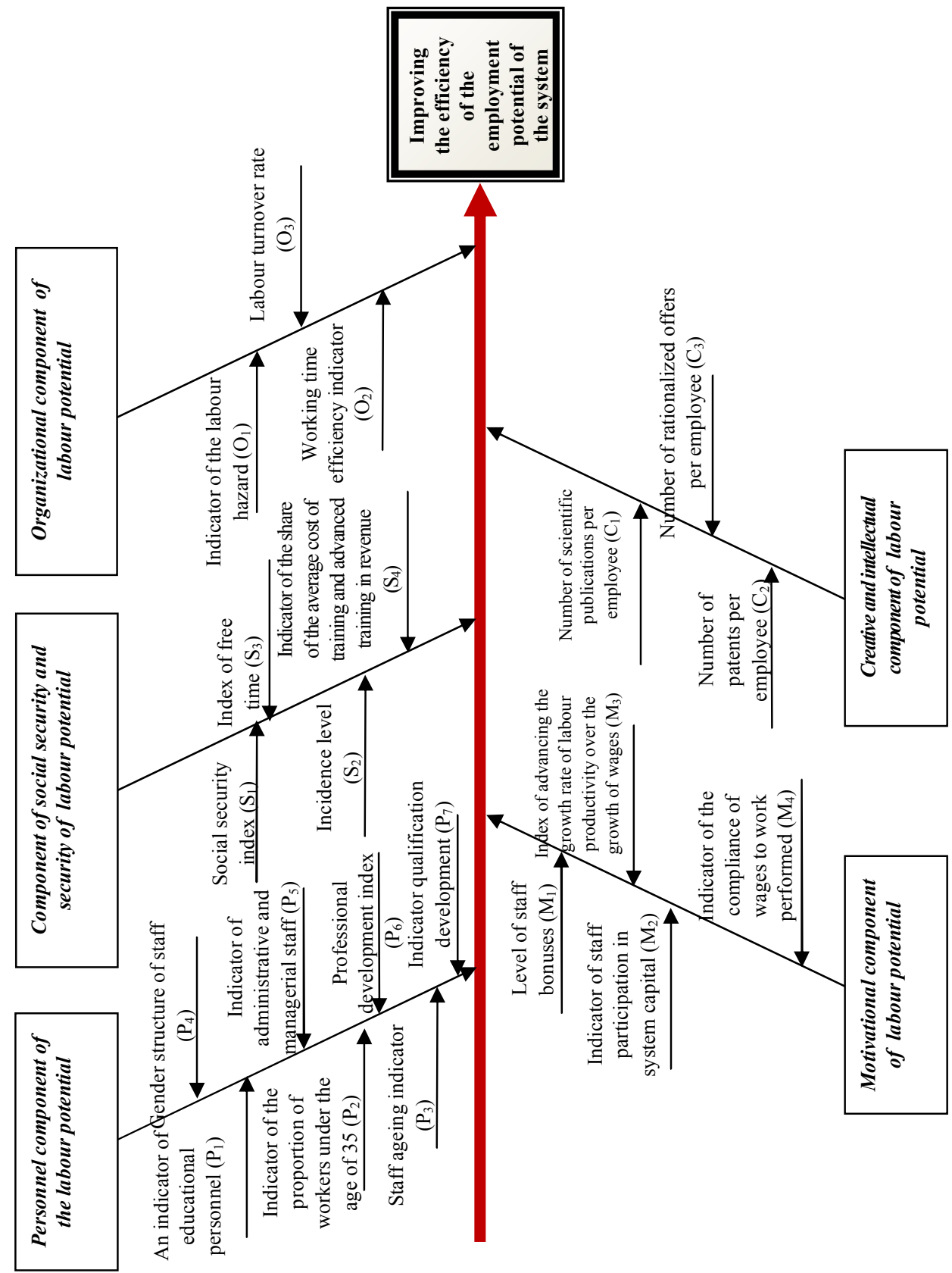

Fig. 2. Ishikawa diagram to improve the efficiency of the labour potential of the socio-economic system

On the basis of the labour potential assessment method "labour potential radar", the labour potential of the socio-economic system was evaluated for 2015-2018 (Fig. 3).

It should be noted that the first two stages characterize the current state of labour potential, that is, the above economic tools present a general picture of labour potential, respectively, they 
do not enable to rank the factors in order of importance (priority).

Stage 3. Construction of a Pareto chart.

The search for solutions to these problems begins with their classification by individual factors in order to clarify the main ones, that is, those that are associated, for example, with the greatest costs. To identify the main factors build Pareto charts and then make their analysis. The Pareto diagram makes it possible to distinguish an «important minority» compared with the "unimportant majority".
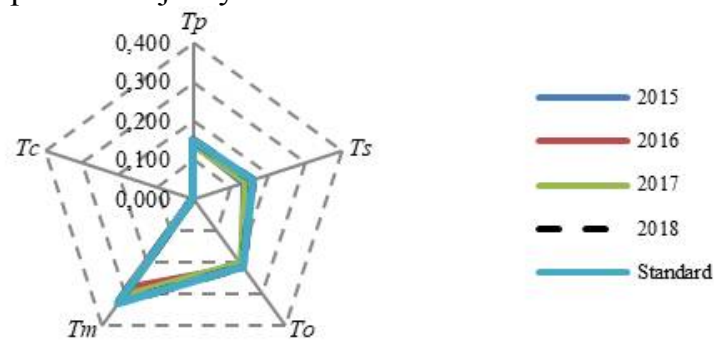

Fig. 3. Radar of labour potential of the socio-economic system in 2015-2018

Thus, the use of the Pareto chart allows modern enterprises to identify $20 \%$ of the factors that determine $80 \%$ of the total result of socio-economic systems. Based on the Ishikawa chart data, a system of indicators has been defined that characterizes our main problem and calculated the rate of change, and according to the developed scale for evaluating the results obtained, the dynamics of factor changes (Table 1), the points are distributed among the indicators.

Table 1. Scale score for the indicator

\begin{tabular}{|c|c|c|c|}
\hline \multicolumn{2}{|c|}{ Stimulator scale (C), points } & \multicolumn{2}{c|}{ Scale de-stimulators (D), points } \\
\hline $\mathbf{0}$ & $<100$ & 0 & $>150$ \\
\hline $\mathbf{1}$ & $100-110$ & 1 & $133-150$ \\
\hline $\mathbf{2}$ & $111-121$ & 2 & $122-132$ \\
\hline $\mathbf{3}$ & $122-132$ & 3 & $111-121$ \\
\hline $\mathbf{4}$ & $133-150$ & 4 & $100-110$ \\
\hline $\mathbf{5}$ & $>150$ & 5 & $<100$ \\
\hline
\end{tabular}

The ranking of indicators is carried out in accordance with the assigned points. At the next stage, the Pareto data for the socio-economic system is calculated by a cumulative total.

According to the principles proposed by Pareto, a graph is plotted: to the left of the intersection point, there are factors that provide $80 \%$ of the result.

The results show that the effectiveness of the labour potential of the socio-economic system for 2015-2018 in general, it is determined by an indicator of «ageing» of personnel, an indicator of an occupational hazard, an indicator of labour turnover, an indicator of a business career.

Stage 4. ABC analysis. After identifying the problem by constructing a Pareto chart from the results, it is important to determine the reasons for its solution. It is necessary to solve it. When using the Pareto chart to identify performance and causes, the most common method is $\mathrm{ABC}$ analysis.

The results of the $\mathrm{ABC}$ analysis are shown in fig. 4.

The calculations made it possible to assert that the indicators of group A are $18,2 \%$, which are managed by the greatest influence on the state of the labour potential of the socio-economic system for 2015-2018, namely: the indicator of «ageing» of personnel, the indicator of occupational hazard, the indicator labour turnover and a business career indicator. 


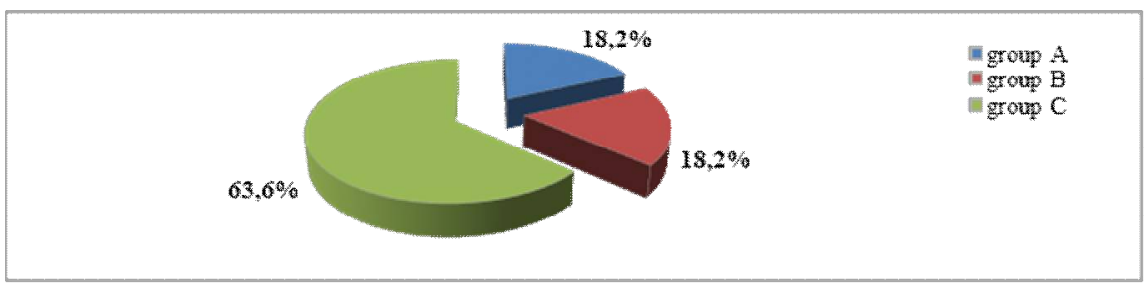

Fig. 4. Summarizing the results of the ABC analysis of the socio-economic system for 2015-2018

\section{Conclusion}

Thus, in accordance with the stated goal of the study, the authors of the article developed recommendations for solving theoretical and practical issues and problems related to the formation and development of the labour potential of the system. As a result of the study of a set of methodological tools and methodological tools that will be used in the course of reproduction and adjustment of the state of the labour potential of the socio-economic system, a methodology is proposed for monitoring the labour potential of the system according to a certain system of indicators. The article tested the proposed methodology based on the results of the socio-economic system of the micro level. The formation and development of the labour potential of the socio-economic system involves the creation of conditions for the full use and realization of the labour potential at all levels of management. For this, it is necessary to ensure the improvement of the governance mechanism itself in the socio-economic system through the use of an organizationalmethodological model for assessing the labour potential of the socio-economic system.

\section{References}

1. Yu. G. Odegov, G. G. Rudenko, Labour Economics: textbook, Moscow (2011).

2. S. G. Radko, Labor potential as a socio-economic category, St. Petersburg (2010).

3. A. A. Ledneva, Methodology for assessing the efficiency of using human resources. Cybernetics, 4-8 (2010).

4. E. D. Lipatova, Yu. A. Yukhtanova, Study of methods for assessing labor potential and labour resources. Student Forum: electron. scientific journals, 21 (21), (2017).

5. V.F. Potudanskaya, L. V. Trunkina, Evaluation of the labour potential of the personnel of the enterprise, Business. Education. Right, Bulletin of the Volgograd Institute of Business, 4 (17), 96-101 (2011).

6. A. N. Fleenko, M. O. Barancheev, Methods for assessing the labour potential of an organization. Scientific world, 8-14 (2015).

7. N. R. Hadasevich. Evaluation of labor potential: approaches and methods, Cybernetics, 6, 8-16 (2014).

8. O. V. Posilkina, O. A. Yaremchuk, Yu. S. Bratishko, Modern approaches to the assessment and management of the labour potential of pharmaceutical companies, Pharmaceutical Journal. K. 5, September-October, 3-9 (2006). 